\title{
Círculos epistemológicos: reflexões sobre uma abordagem de pesquisa freiriana
}

\author{
Epistemological circles: reflections on a freirian research approach
}

\author{
Aline Accorssi \\ Doutora em Psicologia \\ Universidade Federal de Pelotas - UFPel. \\ Pelotas, Rio Grande do Sul - Brasil. \\ alineaccorssi@gmail.com \\ Julia Clasen \\ Mestra em Educação \\ Universidade Federal de Pelotas- UFPel. \\ Pelotas, Rio Grande do Sul- Brasil. \\ clasenjulia1@gmail.com \\ Álvaro Veiga Júnior \\ Mestre em Educação \\ Universidade Federal de Pelotas- UFPel. \\ Pelotas, Rio Grande do Sul- Brasil. \\ avj.pedagogia@mail.com
}

\begin{abstract}
Resumo: Neste artigo propomos uma reflexão de cunho teórico sobre a prática de pesquisa qualitativa a partir de contribuições freirianas. Nosso objetivo é discutir acerca das potencialidades dos Círculos Epistemológicos para a construção de investigações dialógicas, críticas e comprometidas com a transformação social. Para isso, primeiro apresentamos a concepção dos Círculos de Cultura e, posteriormente, os pensamos aplicados ao campo da pesquisa, apontando, então, para os elementos que fundamentam tal proposta. Com os Círculos Epistemológicos adotamos a ideia de que a ciência, enquanto um ato de cons(ciência), tem intencionalidades e compromissos com a mudança. Destacamos que as investigações necessitam possibilitar a construção de espaços dialógicos, de reconhecimento e valorização de conhecimentos, rompendo com antigas cristalizações e hierarquias de saberes. Concluímos que é a partir do encontro horizontal e do diálogo que novos conhecimentos, encharcados de mundo, se formam e possibilitam um agir mais consciente na realidade e na prática científica.
\end{abstract}

Palavras chave: círculos epistemológicos; círculos de cultura; pesquisa qualitativa; diálogo.

Abstract: In this article, we propose a theoretical reflection on the practice of qualitative research based on Freirian contributions. Our objective is to discuss the potential of Epistemological Circles for the construction of dialogical, critical, and committed investigations with social transformation. For this, we first present the concept of Culture Circles. following, think about how they are applied to the field of research, pointing to the elements that underlie such proposal. For Epistemological Circles, we adopt the idea that science, as an act of conscience, has intentions and commitments with the change. We emphasize that investigations need to enable the construction of dialogic spaces, recognition, and appreciation of knowledge, breaking with old crystallizations and hierarchy of knowledge. We conclude that it is from the horizontal meeting and dialogue that new knowledge, drenched in the world, is formed and enables a more conscious action in reality and scientific practice.

Key-words: epistemological circles; culture circles; qualitative research; dialogue.

Cite como

(ABNT NBR 6023:2018)

ACCORSSI, Aline; CLASEN, Julia; VEIGA JÚNIOR, Álvaro. Círculos Epistemológicos: reflexões sobre uma abordagem de pesquisa freiriana. Dialogia, São Paulo, n. 39, p. 1-14, e20418, set./dez. 2021. Disponível em: https://doi.org/10.5585/39.2021.20418.

American Psychological Association (APA)

Accorssi, A., Clasen, J., \& Veiga Jr, Á. (2021, set./dez.) Círculos Epistemológicos: reflexões sobre uma abordagem de pesquisa freiriana. Dialogia, São Paulo, 39, p. 1-14, e20418. https://doi.org/10.5585/39.2021.20418. 


\section{Introdução}

Toda pesquisa tem uma pergunta ou um problema de partida. Sem a dúvida, a interrogação e a curiosidade, não é possível o fazer investigativo. Pesquisar é direcionar esforços visando conhecer algum fenômeno ou fato (ACCORSSI \& SCARPARO, 2017). Para isso, costumamos fazer o uso de diferentes fontes de informações e/ou dados, bem como diferentes percursos ou desenhos investigativos. Nesse processo, os aportes teóricos, os instrumentos, bem como os desenhos de pesquisa adotados pelos/as pesquisadores/as são escolhas. A opção, por exemplo, de um ou outro delineamento ocorre a partir da natureza do objeto, do tipo de pergunta que nos fazemos e das perspectivas epistemológica e ontológica adotadas no estudo.

Neste artigo, construído como um ensaio teórico, pretendemos discutir um desses possíveis delineamentos de pesquisa de cunho qualitativo, uma proposta ainda pouco debatida e que tem origem naquilo que conhecemos como "Círculo de Cultura". Ou seja, seguimos aqui um operador central da obra freiriana e o ampliamos para o campo metodológico, buscando enriquecer a prática de pesquisa em consonância com nossos pressupostos acerca do conhecimento e da construção do ser humano. Trazemos, assim, a proposta de Círculos Epistemológicos apresentada, inicialmente, por Romão et al. (2006) e, posteriormente, desenvolvida e/ou empregada em outros estudos, tais como Accorssi (2011), Freitas (2014), França (2014), Camargo (2020) e Clasen (2020).

Nosso objetivo, portanto, é refletir no que tange às potencialidades dos Círculos Epistemológicos para a construção de pesquisas dialógicas, críticas e comprometidas com a transformação social. Para isso, em um primeiro momento discorremos sobre a proposta dos Círculos de Cultura para, então, pensá-los aplicados à prática de pesquisa emancipadora aqui defendida. Vejamos.

\section{Círculos de cultura}

Os Círculos de Cultura surgiram no Brasil e na América Latina a partir do final dos anos 1950 e início dos anos 1960. Sistematizados por Paulo Freire, foram compreendidos como uma prática pedagógica democrática e libertadora, em oposição às práticas bancárias largamente difundidas no contexto da educação brasileira. Parte-se do pressuposto de que todas as pessoas possuem uma forma própria de saber, sendo que esse saber tem em si valor, uma vez que representa experiências de vida. Do mesmo modo, cada cultura "representa um modo de vida e uma forma original e autêntica de ser, de viver, de sentir e de pensar de uma ou de várias comunidades sociais" (BRANDÃO, 2008a, p. 77). Disso decorre o que muito se tem destacado da obra freiriana: não há saber mais ou saber menos; há saberes diferentes, vistos e formulados a partir de vivências e 
contextos únicos. Nesse sentido, de acordo com Brandão (2008a), nos Círculos de Cultura o diálogo não é uma simples metodologia ou técnica de ação grupal. O diálogo é entendido e tomado como a "própria diretriz de uma experiência didática central no suposto de que aprender é aprender a 'dizer a sua palavra”' (BRANDÃO, 2008a, p. 77).

O aprendizado, nos Círculos de Cultura, ocorre em “reciprocidade de consciências". Em outras palavras, não há um/a professor/a que tematize ou ensine; há um/a coordenador/a que propicia as condições necessárias para a dinâmica do grupo. Em diálogo circular, todos/as se intersubjetivam mais e mais, assumindo assim, criticamente, o dinamismo de sua subjetividade criadora (FREIRE, 1987). Todos/as juntos/as, em círculo e em colaboração, reelaboram o mundo e, ao reconstruí-lo, percebem que, embora o tenham criado, esse mundo não é para eles/as. Ou, nas palavras de Fiori (1987, p. 46), esse mundo que é "humanizado por eles, esse mundo não os humaniza. As mãos que o fazem não são as que o dominam. Destinado a liberá-los como sujeitos, escraviza-os como objetos". É preciso, portanto, retomar o movimento de consciência a partir das situações vividas, a partir da concretude do cotidiano.

Porém, como fazer isso? Paulo Freire, mais uma vez, nos fornece pistas e diz que ninguém educa ninguém, mas também ninguém se educa sozinho/a. Nos Círculos as pessoas dispõem-se em roda, de tal modo que nenhum/a integrante ocupe um lugar proeminente. Nele, a partir do diálogo, todos/as crescem, todos/as se arriscam na aventura do pensar criticamente o mundo. Nele, "as pessoas educam-se umas às outras e mutuamente se ensinam-e-aprendem, através de um diálogo mediatizado por mundos de vivência e de cultura entre seres humanos" (BRANDÃO, 2008a, p. 78).

De forma mais objetiva, o primeiro momento dos Círculos de Cultura (especialmente pensado e estruturado para os processos de alfabetização de adultos) é destinado ao conhecimento da própria comunidade, da realidade em que - objetivamente - os/as integrantes estão inseridos/as. Isto é, refere-se à pesquisa do universo vocabular e do universo temático partilhado pelo grupo, de onde sairão as palavras geradoras que orientarão os debates posteriormente. Aliás, é importante destacar que essas pesquisas de campo iniciais constituíram-se em uma das experiências daquilo que veio mais tarde a ser chamado de pesquisa participante (BRANDÃO, 2008a).

A partir do mergulho no cotidiano do grupo, ocorre o processamento das informações com o levantamento das palavras geradoras e do universo temático que traduzirá o tema gerador. Tal levantamento constitui a matéria-prima, como diz Brandão (2008b, p. 264), "de um trabalho coletivo de criação de saberes e de aprendizagem de ler palavras e ler o mundo”. Disso decorre o 
que ficou conhecido como tematização, ou seja, o processo pelo qual temas e palavras geradoras são codificados e decodificados, buscando descortinar o seu significado social e ampliando o conhecimento de todos/as sobre a própria realidade. A ideia, aqui, não é transmitir conteúdos específicos, mas, conforme Dantas e Linhares (2013), despertar uma nova forma de relação com a experiência vivida.

Nesse movimento, todos/as são motivados/as a participar do livre debate, incentivados/as pela apresentação de fichas de cultura ou materiais que, de modo simples, ilustrem e incentivem a participação. A problematização torna-se um momento decisivo da proposta e reflete a busca de mudança da visão ingênua de estar no mundo por uma perspectiva crítica, a qual incorpora a intenção de transformar ou a própria transformação do contexto vivido. Assim, o trabalho do/a coordenador/a do grupo é possibilitar que todos/as falem, participem, exponham-se com suas palavras, suas ideias, seus pensamentos e, sobretudo, a partir de suas próprias memórias e experiências de vida (BRANDÃO, 2008b). O diálogo, dessa maneira, é elemento-chave que, desde uma concepção freiriana, possibilita a ampliação da consciência crítica acerca da realidade. A horizontalidade entre os/as participantes, a amorosidade, a humildade, entre outras características, tornam os Círculos um lugar acolhedor para que todos/as possam se sentir e ser "gentes" em processo de transformação com a figura $\mathrm{do}(\mathrm{s}) / \mathrm{a}(\mathrm{s})$ outro(s)/a(s). Aliás, a "gentificação" é um processo de humanização, um processo de Ser Mais.

A partir dessa síntese do modo de trabalho freiriano, vemos que, de fato, a leitura do mundo precede a leitura da palavra. A alfabetização propriamente dita iniciava somente após os movimentos acima descritos terem ocorrido. Em um processo ativo e partilhado, a palavra geradora era trabalhada com seus fonemas, formando novas palavras, existentes ou não, e inserindo-as em "novos feixes de sentido, em pequenas frases que iam se tornando mais elaboradas e complexas ao longo do aprendizado" (BRANDÃO, 2008b, p. 264). Dito isso, passamos agora à proposta de ampliação dos Círculos de Cultura para os espaços de pesquisa engajados e comprometidos com a transformação social.

\section{Círculos epistemológicos}

Importante situar, desde já, que não compreendemos os Círculos Epistemológicos como um instrumento de pesquisa que possa ser aplicado a quaisquer investigações. Nossa intenção neste momento é discorrer sobre o que ele é e, sobretudo, visibilizar tal prática ou desenho de pesquisa a partir de suas intencionalidades emancipatórias (BAUER; GASKELL; ALLUM, 2008). 
De forma mais objetiva, podemos dizer que os Círculos Epistemológicos são espaços democráticos e interpretativos utilizados no fazer investigativo. $\mathrm{O} / \mathrm{a}$ pesquisador/a que o utiliza é provocado/a a romper com representações naturalizadas de que somente ele/a teria um conhecimento capaz de compreender a realidade analisada. A própria noção de sujeito de pesquisa, enquanto objeto, é tensionada. Nessa perspectiva, todos/as são "pesquisandos/as" (ROMÃO et al., 2006) que, uma vez que pesquisam, também são pesquisados/as; ou seja, os lugares de análise e de enunciação circulam no grupo. Tal posicionamento está baseado na premissa freiriana de que não há um/a que sabe mais do que outro/a; há, sim, saberes diferentes produzidos em contextos também diversos. Uma vez que os "pesquisandos/as" atuam ativamente no processo interpretativo - são, ao mesmo tempo, autores/as de sua própria história e da materialização das interpretações e das análises, portanto corresponsáveis pela pesquisa -, a própria noção de autoria fica relativizada e merece ser problematizada (ACCORSSI, 2011).

Importante destacar que não ignoramos a existência de saberes diversos e hierarquizados acerca daqueles/as que ocupam os Círculos. Contudo, a proposta que se coloca é de superar o sentido classificatório que atribui valor social a esses saberes. Para que o diálogo democrático ocorra, é proposta uma revisão sobre concepções estagnadas e objetivadas como verdades únicas, que decorre do encontro com outros saberes, em uma relação dialógica formativa dos sujeitos.

A dinâmica operacional dos Círculos Epistemológicos inicia-se com o levantamento de questões que desestabilizam a cristalização do pensamento social e que induzem o processo reflexivo crítico dos sujeitos à formulação de compreensões acerca da realidade. Mais do que respostas, o fazer científico presente nos Círculos Epistemológicos corresponde a uma busca por novas perguntas que movimentam o processo de consciência. Isso porque, conforme Guareschi (2012), a consciência é um processo infinito de busca e de consecução de respostas. Isto é, ela se revela a partir do quanto de respostas damos às perguntas que rodeiam a nossa realidade.

O diálogo, aqui, mais uma vez, demonstra-se como uma categoria central na busca pela consciência e pela transformação. Em Pedagogia do Oprimido (1987, p. 51), Freire dedica parte da obra para mapear o que isso significa enquanto prática educativa libertadora. Ele nos diz: não há diálogo "se não há um profundo amor ao mundo e aos homens". E segue: "Sendo fundamento do diálogo, o amor é, também, diálogo”. O conceito de amorosidade, aliás, está pautado no compromisso com o/a outro/a, que está "engravidado da solidariedade e da humildade" (FERNANDES, 2008, p. 37). Em outras palavras, queremos enfatizar que no fazer investigativo, para além das regulamentações dos comitês de ética, é preciso que haja o compromisso, o respeito 
e a sensibilidade suleando ${ }^{1}$ nossas práticas. O termo "sulear" nos remete à necessidade de contextualização geográfica e histórica na práxis investigativa e educadora. Sulear representaria, assim, a desalienação ao denunciar a opressão do norte-ocidente, dos países imperialistas e, portanto, do colonialismo. Essa sensibilidade é prática coerente com o conhecimento situado ao anunciar a conscientização por desvelamento da realidade concreta.

O diálogo, por conseguinte, implica o desenvolvimento de uma práxis social específica, a saber, o compromisso entre a palavra dita e a nossa ação humanizadora. É a partir dele, do diálogo, que podemos olhar o mundo e a nossa existência como processo, como algo em construção, como realidade inacabada e em constante transformação (ZITKOSKI, 2008, p. 130). Sendo assim, não podemos banalizá-lo ou reduzi-lo a um instrumento metodológico. O verdadeiro diálogo - crítico, respeitoso, comprometido com o/a outro/a - potencializa os "saberes que se entrecruzam nos espaços de aprendizagens, organizando suas práticas e suportando sua articulação na totalidade social onde o que está em jogo é a apropriação social do conhecimento" (LOUREIRO; FRANCO, 2012, p. 21). Através do diálogo, o conhecimento - desde a prática de pesquisa que defendemos é formado e concepções cristalizadas são rompidas, visando o processo de conscientização.

Mas como isso ocorre? Novamente, inspiradas nos Círculos de Cultura, voltamo-nos à investigação da realidade em que os/as "pesquisandos/as" estão inseridos/as e, junto deles/as, identificamos as unidades epocais. Ou seja, em consonância com Romão et al. (2006), procuramos uma temática mais ampla que se constitui em uma unidade categorial acerca de uma visão de mundo, a qual comporta unidades menores, que são os temas geradores. Os temas geradores, no campo da pesquisa, tornam-se hipóteses geradoras que nos permitem procurar e construir novos conhecimentos.

Assim, Romão et al. (2006) nos apresentam algumas funções do/a investigador/a no Círculo Epistemológico, que aqui merecem destaque: 1) é pesquisador/a cultural prévio/a da realidade, uma vez que procura encontrar unidades epocais e hipóteses geradoras; 2) é animador/a epistemológico/a, que provoca a participação de todos/as em torno das hipóteses geradoras; 3) é treinador/a de mergulho que, com olhar crítico, partilha dúvidas, incertezas, a movimentar o pensamento no sentido de ir além da superfície dos fatos e discursos. Além disso, cabe ressaltar que o que se procura é penetrar "nas profundidades da realidade e encontrar os nexos significativos

\footnotetext{
1 "Sulear" é um termo utilizado por Paulo Freire, em Pedagogia da Esperança, para chamar a atenção dos leitores no tocante à conotação ideológica do termo "nortear".
} 
das estruturas e dos processos” (ROMÃO et al., 2006, p. 184) junto com quem está encharcado/a de sentido e significado, pois vive tal realidade.

Para finalizar este ponto, importante retomar o seguinte: o Círculo Epistemológico permite que, a partir do encontro de pessoas (pesquisador/a e "pesquisandos/as"), os/as "pesquisandos/as" reflitam sobre o objeto investigado mobilizados/as por uma hipótese ou questão geradora que leva ao debate. A partir dessa provocação, um conjunto de enunciações das situações existenciais se expressam, podendo estar carregadas de emoção. "Pesquisandos/as" e pesquisador/a analisam juntos/as temas e subtemas, codificam e decodificam, movimentam o pensar, problematizando as situações. Ao fazer isso, de acordo com Romão et al. (2006), eles/as denunciam as condições de existência, movem-se via ação-reflexão-ação e buscam saídas ou transformações na realidade. Logo, a pesquisa se faz, a intervenção ocorre e a consciência de todos/as se amplia.

Dessa maneira, a práxis educativa ultrapassa a noção de pesquisa tradicional e tem papel conscientizador daqueles/as que participam dos Círculos. Por meio do encontro com o/a outro/a, conhecimentos se formam e perpassam os sujeitos em seu sentido mais pleno. Esse aspecto construtor característico dos Círculos Epistemológicos expressa a potência presente, com o objetivo de vivenciar a conscientização sensível dos sujeitos a partir do encontro dialógico proposto.

\section{Por que círculos epistemológicos?}

O conhecimento construído nos Círculos Epistemológicos é manifestação de um processo de conscientização capaz de transformar as concepções que os sujeitos têm da realidade e, consequentemente, a sua atuação sobre ela. Se toda ciência é, antes de tudo, um ato de (cons)ciência (ROMÃO et al., 2006), podemos dizer que o fazer investigativo, ou o ato de indagação sobre a realidade, que conduz o processo dialógico formativo presente nos Círculos Epistemológicos, refere-se à construção de uma práxis social, a qual exige uma interpretação consciente da sociedade. Em outras palavras, concordamos que

a possibilidade de pronunciar o mundo, na dialética ação-reflexão mediada pela linguagem-pensamento, faz parte do processo de constituição do sujeito. Por isso Freire deu tanta ênfase ao diálogo (como palavra que não pode ser privilégio de poucos) e ao movimento que a constitui (ação e reflexão), que ao objetivar-se em diálogo comprometido dos sujeitos nomeia e reflete sua práxis. (FRANCO; LOUREIRO, 2012, p. 13-14). 
Os Círculos Epistemológicos são, portanto, um desenho de pesquisa que conduz à promoção de processos emancipatórios dos sujeitos que deles participam. É por meio do diálogo que esse processo ocorre, e, assim, todos/as que participam dos Círculos são sujeitos "em conscientização", que juntos buscam construir uma pronunciação do mundo em comum. Porém, por que se enfatiza tanto a potência do grupo entre iguais?

Para compreender isso, trazemos, neste momento, as três categorias ontológicas freirianas que fundamentam o fazer investigativo aqui defendido. São elas: incompletude, inconclusão e inacabamento (FREIRE, 2011). Entende-se que somos seres incompletos, pois necessitamos dos/as outros/as; inconclusos, porque estamos em desenvolvimento ou evolução; e inacabados, já que não somos perfeitos. $\mathrm{O}$ ser humano se distingue dos demais animais, apresentando uma especificidade ontológica, a saber: a possibilidade da consciência de seus "limites". Em decorrência dessa singularidade, acaba por viver uma tensão permanente entre a insatisfação por ser o que é (incompleto, inconcluso e inacabado) e a aspiração por "ser mais" (completo, concluído e acabado).

A superação dessas limitações ontológicas está associada à busca por conhecimentos, que também supera suas limitações individuais. Isso porque, como colocado por Romão et al. (2006), se $\mathrm{o} / \mathrm{a}$ pesquisador/a trabalha individualmente, suas conclusões são incompletas, pois mostram apenas uma perspectiva; inconclusas, visto que representam apenas um estágio dentro de um conjunto de conhecimentos socialmente acumulados; e inacabadas, porque são mais incompletas do que as construídas por sujeitos coletivos. Baseia-se, portanto, na premissa freiriana de que não há um/a que sabe mais do que outro/a; há, sim, saberes diferentes, produzidos em contextos também diferentes (GUARESCHI, 2012). Uma vez que os/as participantes atuam ativamente no processo interpretativo, são, ao mesmo tempo, autores/as de sua história e da materialização das interpretações e das análises (ROMÃO et al., 2006). Tal perspectiva retoma os princípios da educação libertadora, a qual, por sua vez, busca romper e superar a contradição educador/aeducandos/as, de tal maneira que se façam ambos/as, simultaneamente, educadores/as e educandos/as.

Sendo assim, ao quebrar o esquema vertical, tanto a pesquisa quanto a educação problematizadora afirmam a dialogicidade como princípio suleador das práticas e das relações. Assume-se, consequentemente, a intencionalidade dos processos e toma-se a consciência como consciência de. Afinal, se queremos a libertação dos seres humanos, não podemos começar por alienálos ou mantê-los alienados, como pesquisas tradicionais frequentemente fazem, em especial entre comunidades periféricas ou minoritárias. "A libertação autêntica, que é a humanização em processo, não é uma coisa que se deposita nos homens. Não é uma palavra a mais, oca, mitificante. 
É práxis, que implica a ação e a reflexão dos homens sobre o mundo para transformá-lo” (FREIRE, 1987, p. 67). Isto é, a palavra guarda duas dimensões inseparáveis: a da ação e a da reflexão. Existir é pronunciar o mundo, e isso já é modificá-lo.

Nesse sentido, a construção dos Círculos Epistemológicos não significa uma sobreposição de conhecimentos diferentes, mas a construção de um conhecimento outro. Dito de outro modo: busca-se ultrapassar a simples soma de perspectivas individuais e fomentar a construção de um “sujeito transindividual”. Segundo Romão et al. (2006), “o conhecimento por ele construído não é a soma dos conhecimentos dos indivíduos que o compõem; é mais do que isto: é o conhecimento produzido por um sujeito novo, constituído no processo coletivo de produção do conhecimento" (ROMÃO et al., 2006, p. 181). O conhecimento que emerge desse sujeito representa, então, um saber coletivo, mas não supera por completo a condição ontológica de inacabamento. Ainda assim, tal conhecimento, em alguma medida, transforma as perspectivas individuais em pronunciações coletivas, estando mais próximo da realidade também partilhada.

Para finalizar esse ponto, reafirmamos a relevância dos Círculos Epistemológicos enquanto uma prática de pesquisa que pretende a conscientização dos sujeitos. Isso ocorre com o rompimento do caráter individualista do conhecimento, bem como da hierarquização de saberes como frequentemente se apresenta nas pesquisas. Procura-se estabelecer uma práxis dialógica de transformação das cristalizações de pensamentos de pesquisadores/as e pesquisados/as, aqui entendidos/as ambos/as como "pesquisandos/as". Os Círculos Epistemológicos, logo, indicam uma historicização do mundo e uma humanização dos sujeitos, que através do diálogo de saberes instauram um processo de conscientização.

\section{Correlações entre diálogo e dialeticidade: práxis político-pedagógica}

A problematização da realidade torna-se um componente metodológico central da proposta, por meio do incentivo ao diálogo no grupo e no percurso do convívio com a pluralidade e com as diferenças. É preciso ensinar o sujeito coletivo a avaliar e a se desenvolver, uma vez que isso não ocorre de maneira natural. Ensinar a mover-se na práxis e pesquisar, no aprendizado curioso e dialético da comunicação e da escuta sensível, no levantamento e na sistematização das hipóteses geradoras. Desse modo, há um incentivo na aprendizagem dialógica já na atitude do encontro, pois as posições e as expressões dos/as "pesquisandos/as" são consideradas valiosas como hipóteses que serão comparadas ao movimento de leitura, teorização e avaliadas pelo grupo.

A práxis transformadora evita que a construção do conhecimento seja um somatório acrítico de posições. Quando entranhada na formação de pesquisadores/as, conclama por 
envolvimento ontológico-existencial. Para tal, torna-se busca de mudança da visão ingênua ou naturalizada da existência por uma perspectiva transindividual crítica. Assim, o conhecimento transindividual, participativo-representativo, traz o rastro dos seus processos democráticos. Seria, dessa forma, uma concepção que dialetiza a produção coletiva, para além da reunião acumulada de posições, incorporando a intenção de transformação da realidade.

Se pensarmos nas condições psicossociais que nos atravessam, a formação escolar nas colônias se deu por meio do conhecimento linear, fragmentado e autoritário. O conhecimento, portanto, esteve sempre ligado à ideologia da elite econômica. Para nos situarmos, também é importante observar que as influências norte-ocidentais dominaram o ensino, as subjetividades e culturas durante a história da modernidade, fixando regras de opressão e de classificação condizentes com os interesses coloniais. Nesse caso, predominantemente instituindo seus valores e subalternizando uma maioria, esta destinada à servidão racializada e sexual.

Assim, o conhecimento conservador caracteriza-se por reproduzir a ordem vigente e excluir a justiça social do contexto vivido. No contexto dessa ordem que vigora, a escola como um aparelho colonial é hostil e desinteressante. Além de exigir obediência e promover a competição individual, não ajuda as pessoas a viverem solidariamente, tendo uma visão "própria" e cultural do mundo. No excesso de informações para memorizar, diante das abstrações desconexas, para além de não aprenderem a conviver politicamente, as pessoas, desde a sua infância, não aprendem a se situar no mundo, seja em termos culturais, espaciais ou de tempo. Ao extremo, no ensino conservador, não se interpreta a realidade, não se cogita modificá-la.

No sentido da Educação Popular, é preciso conceber uma unicidade cultural e de classe para ensinar o convívio coletivo e o aprendizado da comunicação emancipadora. A educação que se dedica à formação dos/as "pesquisadores/as" é coerente com esse paradigma. De acordo com Romão et al. (2006, p. 182), “é o diálogo, no sentido freiriano de interação dialético-dialógica das verdades e perspectivas individuais, que dá a dimensão transindividual ao sujeito coletivo e ao conhecimento por ele produzido". Assim como o ensino, contraditoriamente as pesquisas são dependentes das instituições que necessitam mudar, precisam produzir conhecimentos que contribuam com a justiça social, mas enfrentam as estruturas herdadas da exclusão.

Um modo de subversão é acreditar na unicidade que a práxis permite, considerando que a outra pessoa não é uma inimiga. Não pensamos mais que os especialistas em seus lugares por si só sejam superiores e confiáveis. Tal visão, estática e inocente, é substituída por uma dinâmica social crítica, pela atitude do aprendizado, do dialogar curioso com as contradições. Nos ciclos gnosiológicos do conhecimento, aprendemos a cuidar juntos/as, a pesquisar para criar práticas que 
conduzam ao desenvolvimento humano pleno das pessoas em sociedade. Romão et al. (2006, p. 179) dizem que "o sujeito cognoscente coletivo é, certamente, mais susceptível à evolução dentro do ciclo gnosiológico, a que se referia Paulo Freire, imergindo-se como sujeito transindividual, como diria Lucien Goldmann”.

Pensamos na dimensão qualitativa da pesquisa, cuja premissa é "o ser mais para conhecer mais" e melhor, pois se trata de um campo "que tem, na relação social, a razão de sua existência e a força da produção dos seus resultados”. Especialmente na pesquisa, é coerente o convívio democrático, aberto e autocrítico que combata a fixidez e o autoritarismo, seja do conhecimento ou dos papéis e funções dos/as participantes. Sendo a realidade dinâmica, precisamos conhecer e nos conhecer, quase que simultaneamente, pari passu, em movimento relacional. Nos ciclos gnosiológicos, podemos pensar e sentir no papel de "pesquisandos/as", no empenho pela "formação humana biófila" (FREIRE, 1987) ética e esteticamente, interdependente da formação profissional.

\footnotetext{
Ambos os sujeitos, pesquisador e pesquisandos, produzem verdades parciais devido a seu inacabamento, inconclusão e incompletude. O ser humano, conhecedor de suas características limitadoras, torna-se incansável explorador de suas possibilidades de conhecer mais... para ser mais. Saber mais, para ser mais! A epistemologia implica em ontologia e vice-versa. (ROMÃO, 2006, p. 179).
}

Nesse sentido, o diálogo e a dialeticidade não são características mágicas, que preexistem e tudo podem. A criatividade, a autoestima e o respeito precisam ser praticados em gestos e atitudes. Necessitam ser empregados em um ambiente de aprendizagem, na preparação, nos cuidados sociais e ambientais, na atenção sensível, inclusive na arte da estratégia racional e intuitiva que incentive as relações humildes e afetivas a unir os grupos. Não se consegue uma formação dinâmica, responsável e solidária em contextos de contrainformação e manipulados, nos quais o discurso é um, mas a prática do poder é outra.

Sob forte condicionamento norte-ocidental, vivemos um acirramento de posições de egos opinadores, vaidade, negação e conservadorismo. Violência e exclusão alimentam a "consciência necrófila"; a eliminação da alteridade excedente e do diferente é a solução (FREIRE, 1987). O ensino conteudista e disciplinar tem azeitado uma máquina de exclusão e degradação; por outro lado, é tarefa da educação humanizadora compreender essa conjuntura e se posicionar, a fim de não sucumbir e ir além do resistir.

No enfrentamento dos cânones e arbítrios das instituições, em tempos de incerteza e de riscos, há que se valorizar a experiência solidária e criativa dos/as participantes. Entendemos que 
a construção da consciência emancipada conecta-se com a práxis político-pedagógica crítica. Destina-se a desvelar o contexto do discurso da neutralidade da ciência e das instituições de ensino. $\mathrm{Na}$ sua procura por transformação social, enfrenta o desinteresse, a confusão e a consequente alienação na esteira da burocracia e do tecnicismo, instrumentalizados para o mercado neoliberal.

Nesse oceano poluído e devorador, os Círculos Epistemológicos são uma grande possibilidade de exemplificarmos na prática que a formação de pesquisadores sociais não é neutra nem individual. Como dissemos, o diálogo de saberes instaura um processo de conscientização no ensino, na pesquisa e na aprendizagem. Ninguém nasce cientista, nenhum/a cientista é só um nome solitário e heroico. Nos Círculos Epistemológicos, podemos aprender a valorizar a educação ontológica e epistemológica, em razão de a pesquisa ser instada a tender ao democrático, social e humano.

\section{Considerações finais}

Como apresentado ao longo deste artigo, os Círculos Epistemológicos representam um espaço democrático interpretativo instituído pela pesquisa, o qual desafia e tensiona as formas tradicionais de produção de conhecimento. Os/as pesquisados/as são convidados/as a abandonar a passividade ou simplesmente o papel de provedores/as de informações para se tornarem "pesquisandos/as". Do mesmo modo, o/a pesquisador/a é desafiado/a a romper com antigas representações - de que somente ele/a teria um conhecimento capaz de compreender a realidade analisada - para também se tornar "pesquisando/a". Assim, em movimento, ambos/as inauguram um diálogo comprometido, com interpretações e novas perguntas acerca daquilo que buscam entender. Pesquisar também é educar e educar-se, considerando que a modalidade qualitativa envolve o diálogo intersubjetivo no movimento da práxis político-pedagógica. Para pesquisar é preciso estudar e aprender, estando os "pesquisandos/as" eticamente implicados no processo.

A investigação, nos Círculos Epístemológicos, não se limita a uma produção com autoria única, mas compreende um conhecimento que é compartilhado, e desse modo também os resultados e as interpretações da pesquisa o são. Pois, como falamos no início deste trabalho, não é possível enquadrar essa prática de pesquisa em qualquer caso e situação como se fosse apenas uma ferramenta de produção de informações. Mais que isso, os Círculos Epistemológicos abrangem um ato de contraposição a saberes endurecidos e concepções metodológicas que distanciam os sujeitos da pesquisa.

A construção dos Círculos exige algumas premissas para sua real finalidade, a qual é de questionamento da relação opressiva estrutural que desumaniza seres sociais, que retira sua história 
e oculta sua memória. Dessa maneira, o papel principal presente nesta proposição de produção crítica de pesquisa é de conscientização dos sujeitos que participam da sua construção, a fim de que outros sujeitos possam ser também incorporados nesse processo de consciência coletiva, de uma ciência com consciência e de questionamento acerca do caráter natural das relações estruturais produtivas.

\section{Referências}

ACCORSSI, Aline. Materializações do pensamento social sobre a pobreza. 2011. 184 f. Tese (Doutorado em Psicologia) - Programa de Pós-Graduação em Psicologia, Pontifícia Universidade Católica do Rio Grande do Sul, Porto Alegre, 2011.

ACCORSSI, Aline; SCARPARO, Helena. Entrevistas em psicologia social. In: ROSO, Adriane (Org.). Crítica e Dialogicidade em Psicologia Social: Saúde, Minorias Sociais e Comunicação. Santa Maria: Editora UFSM, 2017.

BAUER, Martin; GASKELL, George; ALLUM, Nicholas. Qualidade, quantidade e interesses do conhecimento: evitando confusões. In.: BAUER, Martin; GASKELL, George. Pesquisa qualitativa com texto imagem e som: um manual prático. 7 ed. Petrópolis: Vozes, 2008, p. 17-36.

BRANDÃO, Carlos Rodrigues. Círculo de Cultura. In: STRECK, Danilo; REDIN, Euclides; ZITKOSKI, Jaime José (Orgs.). Dicionário Paulo Freire. ed.1. Belo Horizonte: Autêntica, 2008a, p.76-78.

BRANDÃO, Carlos Rodrigues. Método Paulo Freire. In: STRECK, Danilo; REDIN, Euclides; ZITKOSKI, Jaime José (Orgs.). Dicionário Paulo Freire. ed.1 Belo Horizonte: Autêntica, 2008b p.263-264.

CAMARGO, Tamiê Pages. Mulheres no PEPEU: o poder interruptor da Educação Musical Feminista. Dissertação. 2020. 149 f. Dissertação (Mestrado em Educação) - Programa de PósGraduação em Educação, Faculdade de Educação, Universidade Federal de Pelotas, Pelotas, 2020.

CLASEN, Julia; ACCOSSI, Aline. A gente não se rende. In.: NOGUEIRA, Gilmaro; MHANDI, Nzinga; TRÓI, Marcelo de (Orgs.). Lugar de fala: conexões, aproximações e diferenças. $1^{\text {a }}$ ed./Salvador: Editora Devires, 2020, p.89-94.

DANTAS, Vera Lúcia; LINHARES, Angela Maria Bessa. Círculos de Cultura: problematização da realidade e protagonismo popular. Caderno de educação popular em saúde; volume 2 / Ministério da Saúde, Secretaria de Gestão Estratégica e Participativa, Departamento de Apoio à Gestão Estratégica e Participativa. - Brasília: Ministério da Saúde, 2013, p. 73-76. Disponível em:https://antigo.saude.gov.br/images/pdf/2016/novembro/10/Miolo-Caderno-EPS2.pdf. Acesso em: 20 mai. 2020.

FERNANDES, Cleoni. Amorosidade. In: STRECK, Danilo; REDIN, Euclides; ZITKOSKI, Jaime José (Orgs.). Dicionário Paulo Freire. ed.1. Belo Horizonte: Autêntica, 2008, p. 37-39. 
FIORI, Ernani. Aprender a Dizer a sua Palavra. In: Paulo Freire. Pedagogia do oprimido. Rio de Janeiro: Paz e Terra, 1987, p. 6-14.

FRANÇA, Fabiane Freire. Representações Sociais de Gênero e Sexualidade na escola: diálogo com educadoras. 2014. 187 f. Tese (Doutorado em Educação) - Universidade Estadual de Maringá, Maringá, 2014.

FRANCO, Jussara Botelho; LOUREIRO, Carlos. Aspectos Teóricos e Metodológicos do Círculo de Cultura: uma possibilidade pedagógica e dialógica em educação ambiental. Ambiente \& Amp; Educação, vol. 17, n.1, p. 11-27, 2012. Disponível em: Acesso em:

https://periodicos.furg.br/ambeduc/article/view/2422 30 jul. 2020.

FREIRE, Paulo. Pedagogia da Autonomia: saberes necessários à prática educativa. São Paulo: Paz e Terra, 2011.

FREIRE, Paulo. Pedagogia do oprimido. Rio de Janeiro: Paz e Terra, 1987.

FREITAS, Cristiane Davina Redin. A assistência social na perspectiva dos usuários: representações sociais e ideologia. 2014. 176 f. Tese (Doutorado em Psicologia) - Programa de PósGraduação em Psicologia Social e Institucional, Universidade Federal do Rio Grande do Sul, Porto Alegre, 2014.

GUARESCHI, Pedrinho. Psicologia social crítica: como prática de libertação. Porto Alegre: Edipucrs, 2012.

ROMÃO, José Eustáquio; et al. Círculo epistemológico círculo de cultura como metodologia de pesquisa. Revista Educação \& Sociedade. Ano 9. n 13. Universidade Metodista de São Paulo, 2006. 